\title{
Coating seeds with Trichoderma strains promotes plant growth and enhance the systemic resistance against Fusarium crown rot in durum wheat
}

Zayneb Kthiri ${ }^{1 *}$ (D, Maissa Ben Jabeur ${ }^{2}$, Myriam Machraoui ${ }^{2}$, Samia Gargouri ${ }^{3}$, Khaled Hiba ${ }^{4}$ and Walid Hamada ${ }^{2}$

\begin{abstract}
Background: Fusarium crown rot is one of the major diseases that cause significant yield losses of wheat, and Trichoderma strains were known as an effective biocontrol agent.

Main body: The aim of this study was to evaluate the potential of coating durum wheat seeds of the cultivar "Karim" with 3 different Tunisian strains of Trichoderma sp. (S.INAT, SIO1, SIO2) and the Trichoderma-based commercial product Trianum-T22 on seed germination, seedling growth, and plant defense response against the pathogen Fusarium culmorum. The strains were identified using molecular tools based on sequencing ITS region of ribosomal DNA. The results confirmed at 99\% of homology that the strains were T. harzianum. Under controlled conditions, the coating seeds were released with $400 \mu \mathrm{l}$ of spore suspension at $10^{7} \mathrm{spores} / \mathrm{ml}$. The seed coating with Trianum-P, and S.INAT showed the highest seed germination rates ranging from 85 to $90 \%$ while $5 . \mathrm{IO} 1$ and S.IO2 presented the lowest germination rates with 66 and 68\%, respectively. At 20 days post-infection (dpi) with $F$. culmorum, the treated plants with S.INAT and Trianum-T22 reduced the disease incidence by 53.59 and 51.79\%, respectively than the control. Besides, S.INAT induced two-folds the phenolic compounds level compared to infected control. Further, the peroxidase activity was enhanced by $50 \%$ in average since $10 \mathrm{dpi}$ in plants treated with S.INAT and $\mathrm{SIO} 2$ than the control.
\end{abstract}

Conclusion: The results suggest that seed coating with T. harzianum S.INAT was a promising tool for crop production and protection under field conditions due to both direct antagonist activity and the indirect growth promotion. This strain seems to induce the systemic resistance of plants against foot crown rot disease.

Keywords: Seed coating, Trichoderma sp., Fusarium culmorum, Wheat, Growth promotion, Antioxidative, Systemic resistance

\section{Background}

One of the major problems in agricultural production in the world is soil borne diseases that cause significant economic losses in yield and quality of many important crops (El-Sobky et al. 2019). In Tunisia, durum wheat, which constitutes the largest part of the staple food in

\footnotetext{
* Correspondence: zayneb.kthiri@gmail.com

${ }^{1}$ Laboratory of Genetics and Plant Breeding, National Institute of Agronomy of Tunis, 43, Ave. Charles Nicolle, 1082 Tunis, Tunisia

Full list of author information is available at the end of the article
}

Tunisia and represents around $60 \%$ of cereal area, is very susceptible to Fusarium crown rot (FCR). The FCR has a wide distribution across the cereal growing areas in Tunisia, and is caused by a complex of fungal species including Fusarium culmorum (W. G. Sm.), F. pseudograminearum, F. verticillioides, $F$. avenaceum, Microdochium majus, and $M$. nivale leading to important yield losses up to $44 \%$ (Chekali et al. 2011).

Currently, disease control measures are carried out on a large-scale using agrochemicals such as chemical 
fungicides which are expensive, increases potentially the consequence of environment pollution and health risk for humans and living organisms, with a little effect on biological control and result in the emergence of resistant pathogens (El-Sobky et al. 2019). Use of the most chemical fungicides as seed coatings could not effectively control FCR. The efficiency of the fungicide does not maintain much beyond the seedling stage due to the natural degradation of chemicals ( $\mathrm{Li}$ et al. 2016). Also, Fusarium mycotoxins pose a significant health risk for humans and animals through food and feed prepared from contaminated cereal crops (Błaszczyk et al. 2017). An alternative approach is to rely on the application of natural antagonists, able to counteract the pathogenic and mycotoxigenic potential of natural populations of Fusarium, rather than acting on their saprophytic phase, or capable of stimulating natural resistance responses by the host plant (Scherm et al. 2013). Trichoderma spp. have been drawing the interest of researchers and intensively investigated since they biocontrol pathogens by different mechanisms such as antibiotic production, mycoparasitism, production of cell wall degrading enzymes and competition for nutrients or space (Tian et al. 2018 and El-Sobky et al. 2019). Besides, they are known to induce the plant defense responses, to trigger plant growth by producing growth hormones, antibiosis compounds and cell wall degrading enzymes, and to induce broad spectrum systemic resistance responses (ISR) in leaves (Li et al. 2016). The great economic and industrial interest in Trichoderma spp. has resulted in formulations of regulated and commercialized products for agricultural use (Filizola et al. 2019). Seed coating with Trichoderma spp. is a promising approach, as an integral component of agricultural practice in seed-plant-soil system that can replace chemical seeds treatments, in order to establish seed bio-priming through making beneficial microorganisms (Nagaraju et al. 2012) accessible to the roots of crops (Tavares et al. 2013), and capable of colonizing the rhizosphere at the critical "early germination" stage and therefore facilitating early, healthy and rapid development with improving nutrient uptake and tolerance to stresses (Nagaraju et al. 2012 and Lutts et al. 2016). Furthermore, this approach stands out as the best alternative sustainable disease management strategy since it either can be used to improve soil microbiome and structure, bioremediation of infected soils, eliminate or reduce the need to treat the broad area in which a crop is installed, and can represent a saving in the time and expense to making such wideranging applications (Chatterjee et al. 2018). Therefore, the search of novel indigenous Trichoderma strains with high biocontrol potential for plant disease management is required for the ubiquitous occurrence of Trichoderma ( $\mathrm{Li}$ et al. 2016). It is highly necessary to screen the candidate Trichoderma strains for potential use as a coating seed treatment for the control of Fusarium in durum wheat.

In this context, the objectives of the present investigation were (i) to isolate endogenous (Tunisian) strains of Trichoderma, followed by molecular characterizations of Trichoderma strains using the internal transcribed spacer rDNA (ITS) method; (ii) to evaluate and select Trichoderma strains with high antagonistic activity against basing on the in vitro dual culture plate technique; (iii) to explore the effect of the seed coating approach with these strains on seed germination, seedling growth and the biocontrol capacity against FCR of durum wheat in plants greenhouse assays; and (iiii) to evaluate the potential of the strains on the induction of plant biochemical response (phenolic content and peroxidases activity) in the absence and presence of the disease.

\section{Materials and methods Isolation of the pathogen}

The fungal pathogen F. culmorum (FC) was isolated from brown lesions in wheat roots sampled from severely infected fields from north Tunisia, kindly provided by Dr. Samia Gargouri (National Institute of Agronomic Research of Tunisia). The pathogen inoculum used for plant inoculation were prepared as previously described by Mnasri et al. (2017). To produce macroconidia, a mixture of barely grains (3:1 by volume) was soaked in water overnight in $250 \mathrm{ml}$ glass bottles. Water was decanted and seeds were autoclaved. Afterwards, seeds were soaked in Fusarium liquid culture, and were kept for 2 weeks at $25{ }^{\circ} \mathrm{C}$ in the dark. Conidia were washed from the kernels and the concentration of the conidial suspension was set to $1 \times 10^{5} \mathrm{ml}^{-1}$.

\section{Isolation and identification of the beneficial antagonist Trichoderma strains}

Trichoderma strains were isolated from the rhizosphere of tomato roots sampled from infected fields with Fusarium oxysporum f. sp. radicis-lycopersici of different regions of Tunisia (Table 1) and maintained after purification on Potato dextrose agar (PDA) medium to be used later as an inoculum. The liquid culture of each pure solid culture of Trichoderma strain was produced by scraping the spores in the sterile distilled water from Petri dishes and transferring them to a 250-ml Erlenmeyer flask containing $100 \mathrm{ml}$ of PDB (Potato-DextroseBroth) medium. The liquid culture was then incubated

Table 1 Strains of Trichoderma and origin

\begin{tabular}{llll}
\hline Strains & S.INAT & S.IO1 & S.IO2 \\
\hline Origin & Tekelsa & Sidi bouzid & Sfax \\
\hline
\end{tabular}


on a rotary shaker at $110 \mathrm{rpm}$ and $25{ }^{\circ} \mathrm{C}$ for $7-10$ days and the mycelium was collected by filtration.

The Trichoderma strains were taken from 1-week-old fungal liquid cultures and the DNA was extracted using the innuPREP DNA Mini Kit (Analytik Jena, Jena, Germany). The purity and quality of the DNA was checked using 1.5\% agarose gel electrophoresis and spectroscopically by reading the absorbance at 260 and 280 nm. The universal primers ITS1 (5'-TCGGTAGGTG AACCTGCGG-3') and ITS4 (5' -TCCTCCGCTTATTG ATATGC-3') were synthesized by Carthagenomics (RAN BioLinks SARL, Tunisia) and used to amplify the ITS (Internal Transcribed Spacer) region of ribosomal DNA (White et al. 1990). PCR was performed in a total reaction volume of $25 \mu \mathrm{l}$, containing $10 \mathrm{ng}$ of the template DNA, $1.25 \mathrm{U}$ Taq DNA polymerase and $1 \times$ Taq polymerase buffer ((Promega, Madison, WI, USA), 0.5 $\mathrm{mM}$ of each primer, $200 \mu \mathrm{M}$ of each of the four dNTP. The MiniOpticon Real-Time PCR System built on the MJ Mini ${ }^{\text {Tw }}$ cycler (Bio-Rad Laboratories, CA, USA) was used for PCR with the following program; $5 \mathrm{~min}$ at $94{ }^{\circ} \mathrm{C}$, followed by 30 cycles of denaturation for 1 min at $94{ }^{\circ} \mathrm{C}$, annealing for $1 \mathrm{~min}$ at $55{ }^{\circ} \mathrm{C}$ (Table 2) and extension for $1 \mathrm{~min}$ at $72{ }^{\circ} \mathrm{C}$. PCR products were then purified and sequenced by Carthagenomics (RAN BioLinks SARL, Tunisia). Sequences were submitted to GenBank database through Submission Portal (a World Wide Web sequence submission server available at NCBI home page: http://www.ncbi. nlm.nih.gov). The sequenced data were compared to the GenBank database, using the BLAST tool available on the National Center for Biotechnology Information (NCBI, http://www.ncbi.nlm.nih.gov/BLAST/).

\section{In vitro antagonistic activity of $\mathrm{T}$. harzianum strains against F. culmorum}

The in vitro antagonist activity against FC was evaluated using the dual culture technique according to Li et al. (2016). Mycelial discs of $5 \mathrm{~mm}$ diameter of 1-week old Trichoderma and 1-week-old FC were placed on the opposite sides of Petri dishes containing potato-dextrose agar at equal distance. The control plates contained only Mycelial discs of FC. The experiment was conducted with 3 repetitions for each antagonist and for the control. The plates were incubated at $25 \pm 2{ }^{\circ} \mathrm{C}$ for 5 days in

Table 2 The different seed coating treatments

\begin{tabular}{ll}
\hline $\mathbf{N}^{\mathbf{0}}$ & Seed coating treatments \\
\hline 1 & Coated control \\
2 & Coated Seeds with S INAT \\
3 & Coated Seeds with S. IO1 \\
4 & Coated Seeds with S. IO2 \\
5 & Coated Seeds with Trianum-P \\
\hline
\end{tabular}

the dark and at the end of the experiment, the diameter of mycelia growth was measured to determine the inhibition percentage as following:

$$
\text { Inhibition }(\%)=\frac{(\mathrm{C}-\mathrm{T})}{\mathrm{C}} \times 100 \text {; }
$$

Where $C$ is the radial growth of $\mathrm{FC}(\mathrm{mm})$ alone (control); and $T$ is the radial growth of FC ( $\mathrm{mm})$ in the presence of Trichoderma strains.

\section{Plant experiments}

\section{Seed coating treatment}

Seeds of durum wheat (Triticum durum L.) cv. Karim were chosen for all experiments according to its susceptibility to the soil-borne fungal pathogens (Chekali et al. 2011). Prior to use, seeds were surface-sterilized, soaked for $2 \mathrm{~min}$ in an aqueous solution of $0.6 \%$ sodium hypochlorite, then for $2 \mathrm{~min}$ in $70 \%$ ethanol, and rinsed three times with sterile distilled water. Afterwards, the seeds were coated as described by Ben-Jabeur et al. (2019), The coating technique for each treatment consisted of mixing $40 \mu \mathrm{l}$ of the coating product Agicote Rouge T17 (AEGILOPS Applications, France) with $400 \mu \mathrm{l}$ of the suspension of each Trichoderma culture (Table 2) at a concentration of $10^{7}$ spores. $\mathrm{ml}^{-1}$ (water was used as a control), at a concentration of $10^{6}$ spores. $\mathrm{ml}^{-1}$. Then, the coating mixture was applied progressively to $10 \mathrm{~g}$ of wheat seeds in continuous rotation, until complete adhesion and absorption, to assure homogeneous distribution of the coating mixture among seeds. The product Trianum-P was used as a reference for this experiment; it is a biofungicide marketed by koppert based on $T$. harzianum-T22 (3.65\%) and other components (96.35\%), contained at least $1.0 \times 10^{7}$ colony forming units per gram dry weight, and known to promote plant growth and to control plant diseases (Lascaux and Piron, 2009 and Gveroska, 2017).

\section{Effect of seed coating treatments on seed germination and growth promotion}

After seed coating treatment, the coated seeds were sown in Petri dishes with Hoagland medium (1\% agar). Plates were placed in a growth chamber at $22 \pm 2{ }^{\circ} \mathrm{C}$ with a 12-h photoperiod. The percentage of seed germination was measured at 7 days post-coating (dpc). Subsequently, coated seeds were grown in pots of $16 \mathrm{~cm}$ diameter containing a mixture of standard substrate: perlite $(1: 1, \mathrm{v} / \mathrm{v})$, with a density of four seeds per pot. Pots were maintained under controlled conditions in the growth chamber $\left(22 \pm 3{ }^{\circ} \mathrm{C}, 40-50 \%\right.$ relative humidity, and a photoperiod of 16:8 h light/dark). Plants were irrigated with the nutritive solution (Hoagland) during the course of experiments. Experiments were performed 
using a completely randomized design (CRD) with 6 treatments, and 3 replicates and the pots were rotated 3 times a week to assure uniform growth conditions in the growth chamber. For each treatment, plant samples were taken at $10 \mathrm{dpc}$ to measure the shoot height, the root length, and the plant biomass. The seedling vigor index (VI) was calculated according to the following formula: seedling vigor index $=$ [seedling length $(\mathrm{cm}) \times$ germination percentage (\%)] (Buriro et al. 2011).

\section{Effect of seed coating treatments on F. culmorum disease control}

At stage of 3 to 4 leaves, plants were inoculated by irrigation with the suspension of $F C$ at a concentration of $10^{5}$ macroconidia. $\mathrm{ml}^{-1}$. Control seedlings were irrigated with water only. For each treatment, the incidence was recorded at $10 \mathrm{dpi}$ as the percentage of plants showing browning symptoms on the base of the stem. The evaluation of the disease severity of FCR was scored in the seedling stage at $20 \mathrm{dpi}$ and rated on a $0-5$ scale based on the typical symptoms of browning as previously described by Koycu (2019) as follows: 0, healthy plant; 1, necrotic area is lower than 25\%; 2 , necrotic area is between 25 and 50\%; 3, necrotic area is between 51 and $75 \%$; 4 , necrotic area is greater than $75 \%$; 5 , plant is dead. Disease incidence and severity were averaged among the replicates. Afterwards, the reduction rates (RR) of the disease index (incidence or severity) of FCR by the treatments were calculated as following: $\mathrm{RR}(\%)=\frac{\text { Disease index in control infected plants - Disease index in treated infected plants }}{\text { Disease index in control infected plants }} \times 100$

\section{Effect of seed coating treatments on the antioxidative metabolites in wheat seedlings in the absence and presence of $F$. culmorum}

At $10 \mathrm{dpi}$ representing the time of the emergence of FCR symptoms, samples were taken from both inoculated and non-inoculated plants derived from coated seeds for the quantification of total phenolic content and peroxidases activity which are metabolites involved in the plants' defense response, antioxidative pathway, and lignification. Total phenolic content was estimated by Folin-Ciocalteu method (Singleton et al. 1999). Samples of $500 \mathrm{mg}$ of fresh leaves were ground with $2 \mathrm{ml}$ of methanol (80\%) at $4{ }^{\circ} \mathrm{C}$ and then centrifuged at 1000 $\mathrm{rpm}$ for $10 \mathrm{~min}$. A $100 \mu \mathrm{l}$ of the supernatant was added to the reaction mixture containing $50 \mu \mathrm{l}$ of sodium carbonate (20\%), $1750 \mu \mathrm{l}$ of sterile distilled water and 250 $\mu \mathrm{l}$ of Folin-Ciocalteu reagent (Sigma-Aldrich, Germany). The reaction mixture was well mixed and incubated for $30 \mathrm{~min}$ at $40{ }^{\circ} \mathrm{C}$ and then cooled to room temperature. The optical density was measured at $760 \mathrm{~nm}$ and the amount of phenol was determined using Catechol as the standard and expressed as $\mathrm{mg} \cdot \mathrm{g}^{-1}$ fresh weight (FW). Peroxidase activity was measured according to (Egley et al. 1983); samples of $200 \mathrm{mg}$ of fresh roots and third equal-size leaves were homogenized in $5 \mathrm{ml}$ of $50 \mathrm{mM}$ K-phosphate buffer ( $\mathrm{pH} 5.5)$. After centrifugation at 12, $000 \times g$ for $20 \mathrm{~min}$ at $4{ }^{\circ} \mathrm{C}$, the supernatant was collected as the crude enzyme solution. A reaction mixture was prepared by adding $2.9 \mathrm{ml}$ of $50 \mathrm{mM}$ K-phosphate buffer (pH 5.5), $1 \mathrm{ml}$ of $\mathrm{H} 2 \mathrm{O} 2(0.6 \mathrm{M})$ and $1 \mathrm{ml}$ of $50 \mathrm{Mm}$ guaiacol to $0.1 \mathrm{ml}$ of crude enzyme solution. Protein content of the crude enzyme solution was determined at $595 \mathrm{~nm}$ with bovine serum albumin as the standard using the Bradford assay (Bradford, 1976) by mixing 790 $\mu \mathrm{l}$ of extraction buffer, $10 \mu \mathrm{l}$ of crude enzyme solution and $200 \mu$ l of Bradford reagent (Biomatik, Tunisia). Peroxidases activity was determined with guaiacol at 470 $\mathrm{nm}$ and expressed in unit $\mathrm{mg}^{-1}$ protein.

\section{Statistical analyses}

In order to assess the significance among the effect of Trichoderma species, data were subjected to analysis of variance (ANOVA) using SPSS software (20.0). The antagonism effect of the Trichoderma strains on the pathogen $(\mathrm{Fc})$ growth and the effect of seed coating treatments on growth traits of wheat were determined through a one-factor ANOVA (strains) and (treatments), respectively. The effects of the treatments and infection and their interaction on FCR incidence and severity, and on phenolic content and peroxidases activity were determined through a two-factor (treatments $\times$ infection) ANOVA. The comparison of means was performed using the Duncan's multiple range test (DMRT). All graphics creation was generated in the RStudio environment, using RStudio software 1.1.463 (2009-2018 RStudio, USA).

\section{Results and discussion Identification of Trichoderma strains}

Macroscopic morphology was investigated in the 3 of Trichoderma strains. They showed to be compatible with the description of the genus according to the findings of the literature, and revealed colonies of 1-2 concentric rings with green conidial production in mature colonies (Fig. 1). The mycelium, initially of a white color, acquired green, yellow shades, or remained white, due to the abundant production of conidia (Siddiquee, 2017 and Filizola et al. 2019), which in consistent with the characteristics previously described for this fungus (ElSobky et al. 2019). The preliminary identification of these strains, based on colony morphology observations, was insufficient to reliably determine species. Thus, the identification was further ascertained by molecular analysis based on the sequencing of the ITS region of 


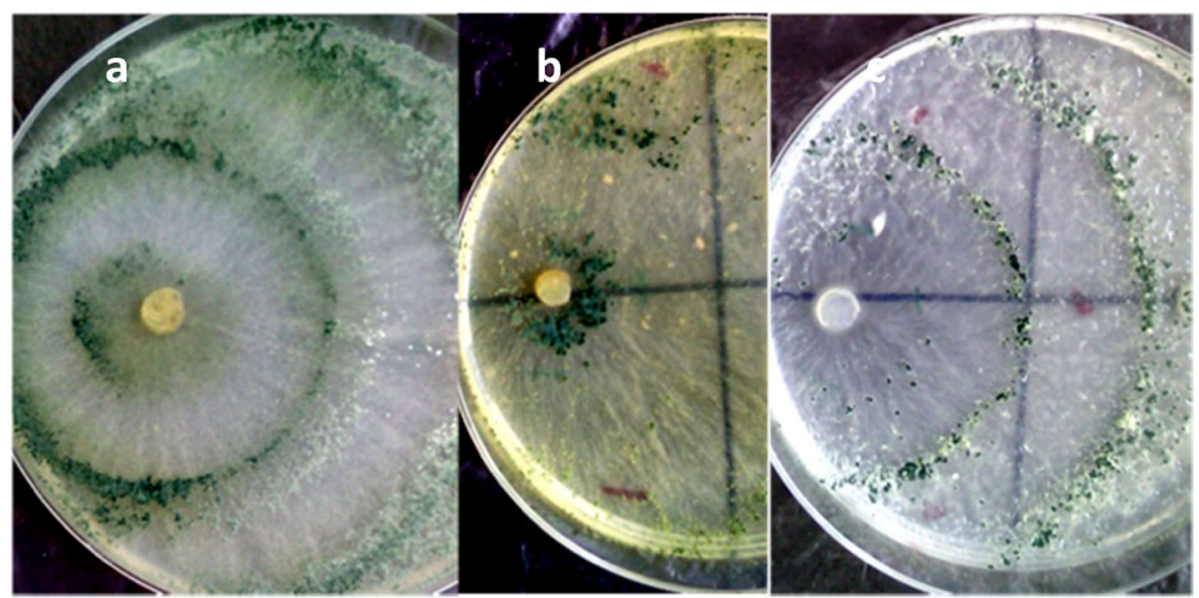

Fig. 1 Macroscopic aspects of T. harzianum strains inoculated in Petri dishes containing PDA as culture medium. a S.INAT. b SIO1. c SIO2

ribosomal DNA. PCR based on ITS primers was used to amplify ITS region and the sequencing data was entered on NCBI site to search BLAST and compare these data with published ITS data. The identity of the isolates was identified as belonging to species $T$. harzianum with homology percentage of $99 \%$ with the published sequence of Trichoderma spp. and sequences were deposited in GenBank (Table 3), which was reported as one of the common species with a widest distribution (El-Sobky et al. 2019).

\section{Evaluation of the antagonistic activity of Trichoderma strains on $F$. culmorum mycelium}

In the dual-culture experiment (Fig. 2), the three Trichoderma strains significantly hampered the mycelial growth of F. culmorum; however, they exhibited different inhibition rates against it. The maximum inhibition was recorded by the strain S.INAT (61\%), with an inhibition zone of $15 \mathrm{~mm}$, followed by S.IO1 (50.3\%), and then S.IO2 (37.66\%).

Testing of the strain of Trichoderma with the highest antagonistic activity is important for developing biocontrol agents. The dual culture experiment indicated that the three $T$. harzianum species were able to repress the mycelium growth of $F$. culmorum with a great variability in the level of the antagonist potential among them. As previously reported, the antagonistic function of the $T$. harzianum species is owing to their competition for nutrients, antibiosis, and mycoparasitism, including their

Table 3 Molecular identification of T. harzianum strains

\begin{tabular}{lll}
\hline Strains & Identification & Accession number \\
\hline $\mathrm{SIO} 1$ & T. harzianum $\mathrm{SIO} 1$ & MT605289 \\
$\mathrm{SIO2}$ & T. harzianum $\mathrm{SIO2}$ & MT605288 \\
S.INAT & T. harzianum S. INAT & KU710282 \\
\hline
\end{tabular}

active metabolism in the production of large amounts of secondary metabolites such as chitinase, b-1, 3glucanase, protease, peptaibols, polyketides, pyrones, terpenes, and polypeptides, that act as potent weapons against other non-beneficial fungi (Li et al. 2016 and ElSobky et al. 2019). This research also proved possible parasitism of $T$. harzianum and competition for space and nutrients. The strain S.INAT displayed the most promising antagonistic potential to prevent the growth of F. culmorum, which deserve attention and further analysis of their ability to control disease development in controlled conditions as well as field experiments. The observed variations regarding the degree of antagonism among the different isolates against the same Fusarium strain may be indicative of the existence of specificity between the antagonist and the potential phytopathogen, suggesting the involvement of various genes and genetic factors interacting with the environment, and highlight the fact that more than one mechanism of action might be simultaneously involved in antagonistic actions (Filizola et al. 2019).

\section{Effect of seed coating treatments on seed germination and seedling growth}

The analysis of variance showed that seed coating treatments significantly affected seed germination, and root and shoot length, plant dry matter, and vigor index $(P=0.001)$ in wheat seedlings (Figs. 3 and 4$)$. At $7 \mathrm{dpc}$, the seed coating with Trianum-P, and S.INAT resulted in the highest seed germination rates (85-90\%), while the control as well as S.IO1 and, S.IO2 resulted in the lowest germination rates (66-68\%) (Fig. 3).

At $10 \mathrm{dpc}$, the seed coating with the reference product Trianum-P had the more remarkable effect on all growth traits compared to the other seed coating treatments (Fig. 4). Compared to the coated control, the strains 


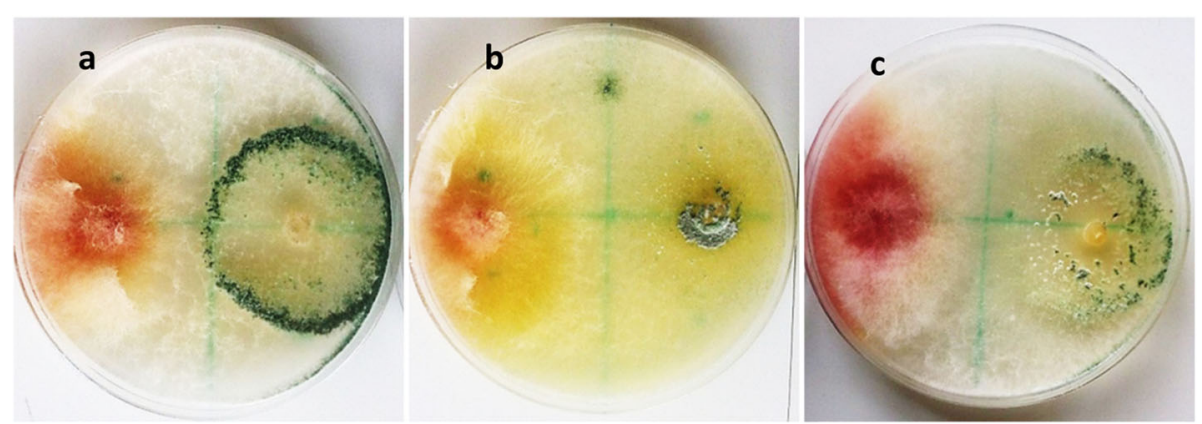

Fig. 2 In vitro antagonist activity of T. harzianum strains and their inhibition rates against $F C$ in the dual-culture. a S. INAT. b SIO1. c SIO2

S.INAT and S.IO2 increased all the growth traits. Specifically, the strain S.INAT resulted in the highest root and shoot length, and the vigor index, while the strain S.IO2 resulted in the highest plant dry matter. The strain S.IO1 was the less effective in the wheat growth promotion (Fig. 4).

Taken into consideration that Trichoderma has a pivotal function as antagonist and growth promoters ( $\mathrm{Li}$ et al. 2016) and that some strains can produce antifungal metabolites while others act as promoters of plant development (Filizola et al. 2019), all the strains were subjected to experiments to evaluate their impact on plant's growth as seed coating treatments. In general, the coating method facilitates the contact between the treatments and the seed, helps beneficial microorganisms to colonize the roots at early stages of growth which give the plants the ability to better assimilate the nutrients (Tavares et al. 2013 and Ben-Jabeur et al. 2019). As expected, the referential product Trianum-P strongly stimulated the seed germination and the root and shoot development of seedling, with higher phenolic accumulation and peroxidases activity. This not only add evidence to the potential of the commercialized strain T22 of Trichoderma to promote plant growth and to control plant diseases (Lascaux and Piron, 2009 and Gveroska, 2017), but also emphasizes the effective future use of this product as a seed coating treatment. Among the tested endogenous Trichoderma strains, the seed coating with S.INAT and S.IO2 seemed to be the most promising seed coating treatments resulting in the promotion of all the growth traits associated with higher phenolic accumulation and peroxidases activity in wheat. Specifically, the strain S.INAT resulted in the highest root and shoot length, vigor index, and phenolic accumulation, while the strain S.IO2 resulted in the highest plant dry matter and peroxidases activity. Indeed, in the absence of stress, peroxidases, and phenolic compounds are involved in the wall-building processes such as lignification and reinforcement of plant structural components (Scherm et al. 2013 and Akbari-Vafaii et al. 2014). Therefore, the stimulation of peroxidases and phenolic accumulation constitutes one of the mechanisms of $T$. harzianum in promoting growth. To summarize, the observed growth promotion could be attributed to (i) seed bio-priming through making S.INAT and S.IO2 capable of colonizing

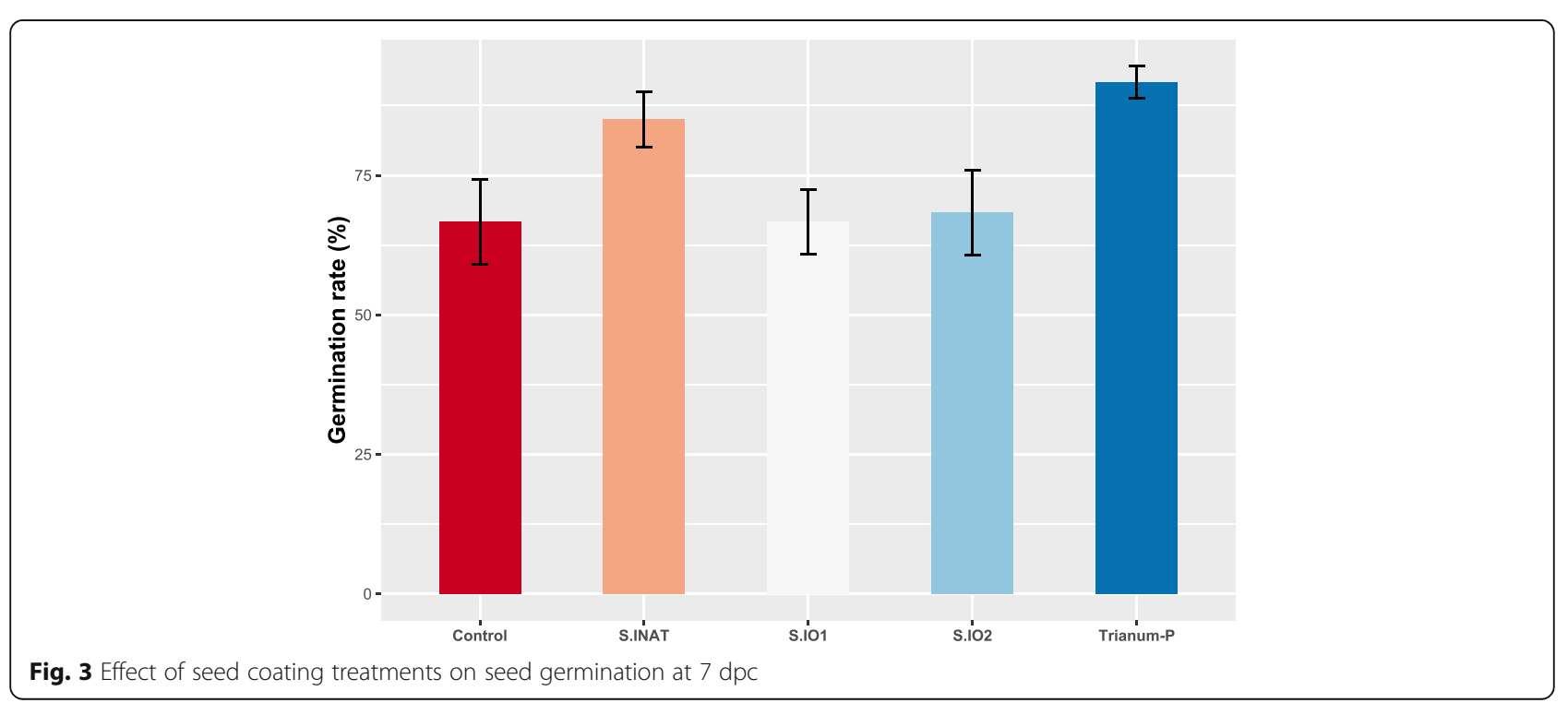



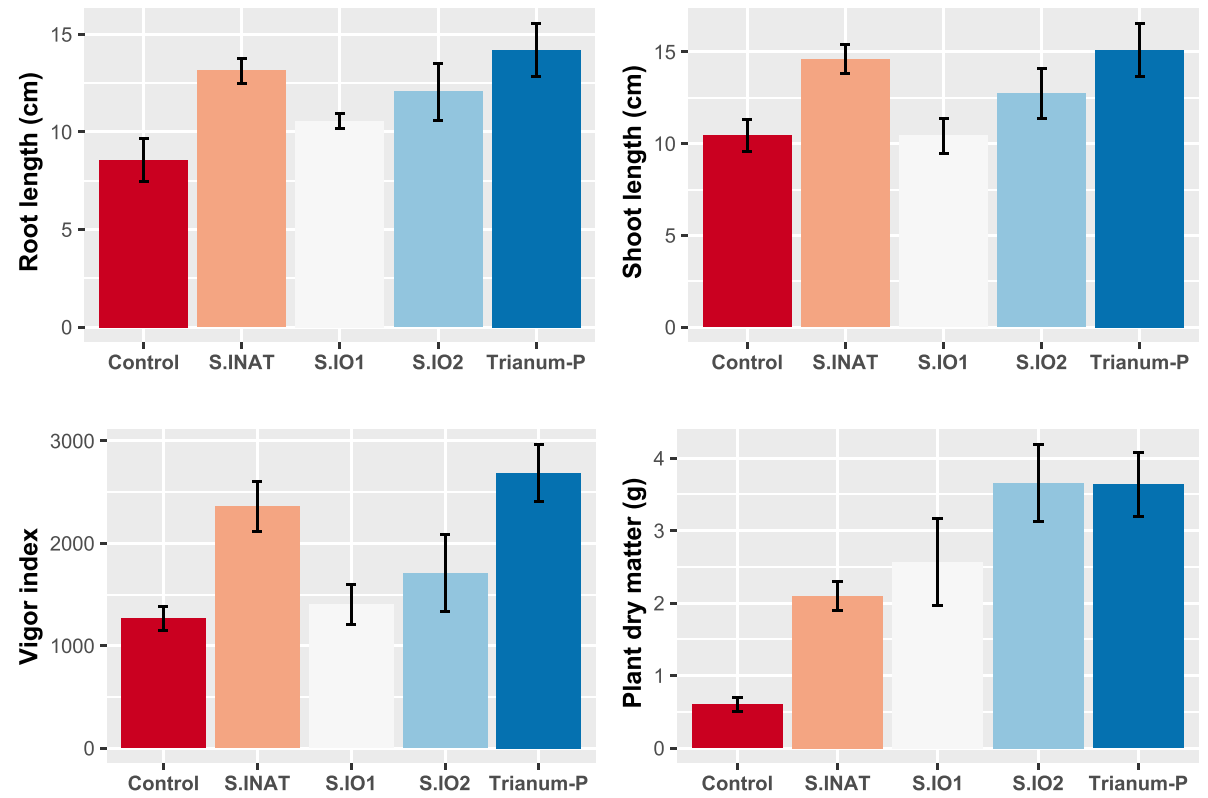

Fig. 4 Effect of treatments on root and shoot length, vigor index, and plant dry matter at $10 \mathrm{dpc}$

the roots at the "early germination" stage and hence facilitating early, healthy and rapid development with improving nutrient uptake (Singh, 2010; Saba et al. 2012; Lutts et al. 2016 and Ben-Jabeur et al. 2019), and (ii) the antagonist effect of $T$. harzianum on decreasing the activity of deleterious root micro flora and inactivation of toxic compounds in the root zone leading to a better root development (Roberti et al. 2008).

\section{Effect of seed coating with $T$. harzianum strains on foot crown rot disease control and the antioxidative defense response in wheat \\ Effect of seed coating with $T$. harzianum on foot crown rot disease control}

The analysis of variance revealed a highly significant effect of the treatments for FCR disease incidence $(p=0.001)$ and severity $(p=0.01)$ (Table 4$)$. In inoculated control plants, the incidence reached $93.3 \%$ at 10 $\mathrm{dpi}$, and the severity reached 3.3 at $20 \mathrm{dpi}$. In general, all seed coating treatments reduced the pathogenic effect of F. culmorum in wheat depicted by a lower incidence and severity of the disease than the control (Fig. 5). Specifically, plants derived from seed coating with S.INAT and Trianum-P were the more remarkable treatments as S.INAT resulting in the highest reduction rate of the disease incidence $(R R= \pm 53.59 \%)$, and Trianum-P resulting in the highest reduction rate of the disease severity by (RR $= \pm 59.69 \%)$ (Table 4$)$.

Moreover, the effect of treatments on growth promotion under the biotic stress was further ascertained based on the pictures showing an enhanced plant development, described by a higher leaf number and/or a higher length of the emerging third leaf, than the control. Captivatingly, the strain S.INAT resulted in a higher leaf number and area at $10 \mathrm{dpi}$, and the highest leaf number at $20 \mathrm{dpi}$.

\section{Effect of seed coating with T. harzianum on the antioxidative system in wheat seedlings}

Analysis of variance (Fig. 6) revealed that seed coating treatment and infection affected significantly, the peroxidase activity and the phenolic content $(p=0.001)$, while their interaction (seed coating treatment $x$ infection) affected significantly only the peroxidase activity $(p=0.001)$. In the absence of the infection, the plants derived from seed coating with all treatments (S.INAT, S.IO1, S.IO2, and Trianum-P) had a higher phenolic content and peroxidases activity, compared to coated control; with a more remarkable increase of phenolic content than peroxidases activity. The S.IO2 was recorded as the most strain inducing peroxidases, while S.INAT was the most strain inducing phenolic accumulation. When challenged with the pathogen Fc, a slight increase of peroxidases activity was recorded in infected control plants than the control plants, while phenolic content remained unchanged. In infected treated plants, the peroxidases activity was magnified and the increase of phenolic content was activated, compared to the infected control plants. The increase rate of both metabolites changed relatively to the different treatments; the strain S.INAT induced the highest phenolic content and peroxidases activity under infection.

At $20 \mathrm{dpi}$, control plants showed the symptoms of basal browning along with a lower foliar development as 
Table 4 Results of one-factor ANOVA for disease incidence and disease severity on plants inoculated with F. culmorum. The F values are shown $\left({ }^{*} p<0.05 ;{ }^{* *} p<0.01 ;{ }^{* *} p<0.001\right)$

\begin{tabular}{|c|c|c|c|c|}
\hline & $\begin{array}{l}\text { Disease incidence } \\
\text { (\%) at } 10 \mathrm{dpi}\end{array}$ & Reduction rate \% & $\begin{array}{l}\text { Disease severity } \\
\text { at } 20 \mathrm{dpi}\end{array}$ & Reduction rate \% \\
\hline Control & $93.3^{\mathrm{a}} \pm 2.8$ & - & $3,3^{\mathrm{a}} \pm 0.57$ & - \\
\hline SINAT & $43.3^{c} \pm 2.8$ & 53.59 & $1.66^{b} \pm 0.57$ & 49.69 \\
\hline $\mathrm{SIO1}$ & $62.3^{b} \pm 2.5$ & 33.22 & $3.0^{\mathrm{a}} \pm 0.0$ & 9.09 \\
\hline $\mathrm{SIO} 2$ & $59.6^{b} \pm 2.5$ & 36.12 & $1.66^{b} \pm 0.57$ & 49.69 \\
\hline Trianum & $45.0^{C} \pm 5$ & 51.76 & $1.33^{b} \pm 0.57$ & 59.69 \\
\hline \multicolumn{5}{|l|}{ ANOVA } \\
\hline Treatments & $111.6^{* * *}$ & & $9.125^{* *}$ & \\
\hline
\end{tabular}

previously reported (Roberti et al. 2008 and Scherm et al. 2013). These symptoms were preceded by an increase in peroxidases activity at $10 \mathrm{dpi}$, with no recorded change in phenolic content. This biochemical response is considered as the triggered defense mechanism occurring at this stage of F. culmorum-wheat interaction in response to pathogenic oxidative and cell death processes. In fact, it is well-established that upon infection plant cells respond with a hypersensitive reaction by the generation of reactive oxygen species (ROS), which induce antioxidative metabolites as catalase, peroxidases, and phenolic compounds (Harrach et al. 2013; Rajeswari, 2014 and Akbari-Vafaii et al. 2014). In this study, phenolic compounds were not induced in control plants which underline the sensitivity of the variety "karim" towards the foot crown rot disease. This is corroborating with the findings showing that phenolic and polyphenolic compounds are present in larger amounts only in Fusarium-resistant plants (Jogaiah et al. 2013 and Akbari-Vafaii et al. 2014).

The seed coating treatments with Trichoderma strains simultaneously enabled plants to more efficiently scavenge ROS or prevent their production by inducing both peroxidases and phenolics, consequently decreased the disease incidence and severity, and promoted the growth of plants under the biotic stress. This could be attributed to: (i) the beneficial antagonist potential of $T$. harzianum that contains spores and produces mycelium growing at the same rate as the roots and protecting them from diseases (Dendouga et al. 2016), and (ii) the induction of the systemic acquired resistance (SAR) depicted by a magnified antioxidant and/or radical scavenging activities especially phenolics which have been shown to exhibit antifungal activity against Fusarium spp. and antioxidant activities (Jogaiah et al. 2018). This result is consistent to previous studies showing that seed treatment of maize with T. harzianum T22 and Th- 8 strains reduces Fusarium verticillioides colonization and induces systemic resistance in maize against this pathogen (Ferriego et al. 2014a, b). Again, in this study, the strain S.INAT outperformed the other seed treatments in terms of disease control and growth promotion as well as peroxidases activity and phenolic content. This suggests that phenolics most likely played a key role in

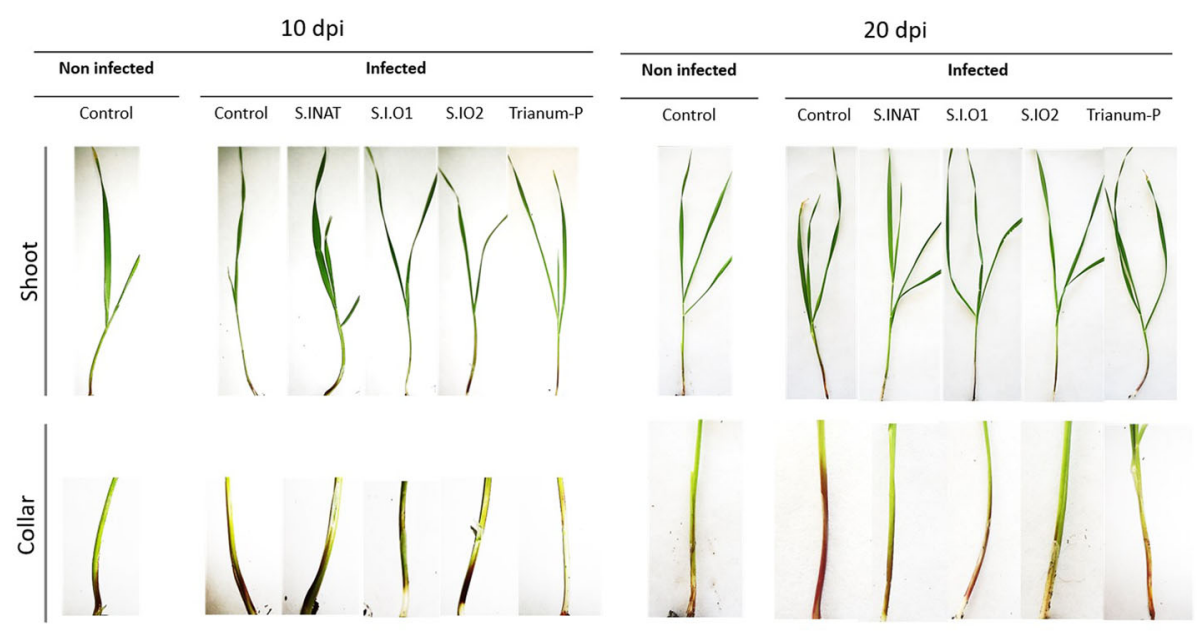

Fig. 5 Incidence percentage of FCR in wheat plants and disease severity of FCR in wheat crown following treatments 

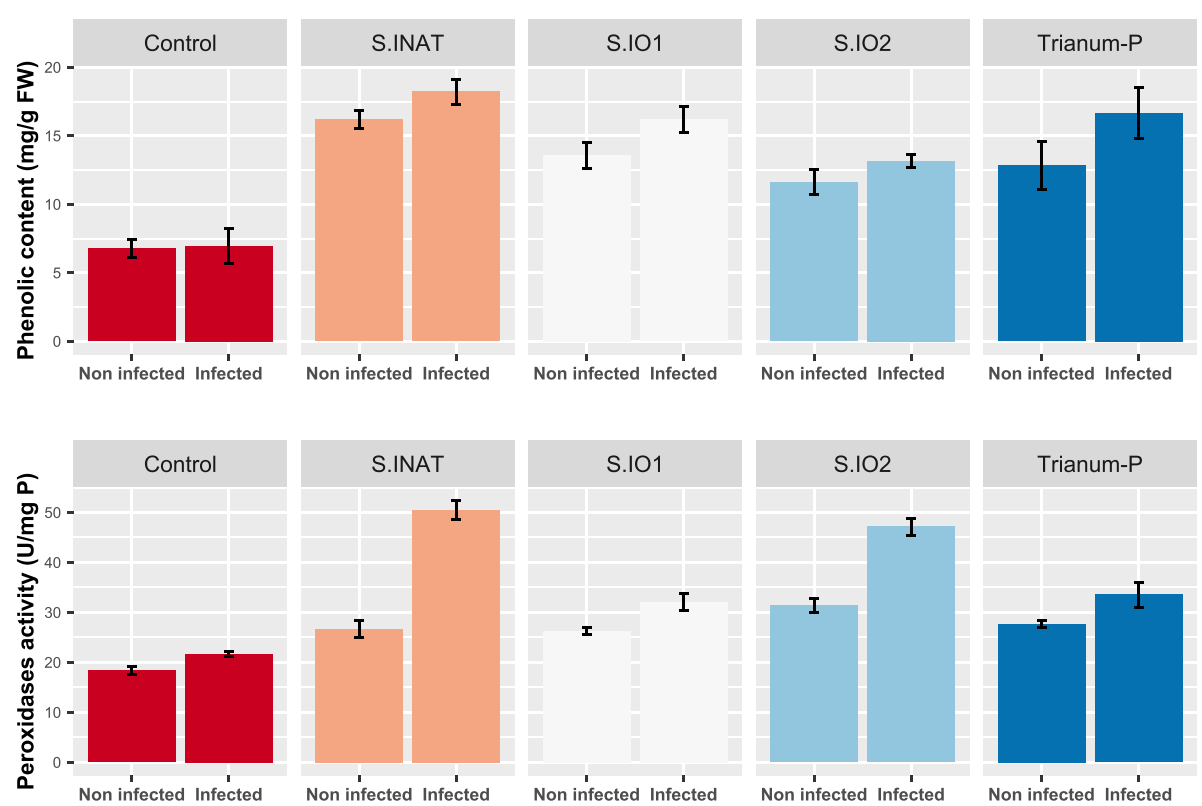

Fig. 6 Effect of both treatments and infection with F. culmorum on total phenolic content and peroxidases activity in wheat leaves at $10 \mathrm{dpi}$

the observed resistance which has been reported to be involved in the cell wall reinforcement and may supply structural resistance to invading pathogens (Schöneberg et al. 2018). This is in line with the findings of LorencKukuła et al. (2007) who demonstrated that the increase in resistance of transgenic flax (Linum usitatissimum) seedlings to F. culmorum was mediated by three key enzymes of flavonoid biosynthesis.

\section{Conclusion}

In conclusion, the results showed that the T. harzianum strain studied had successful biocontrol activity and ability to compete against $F$. culmorum in vitro as well in vivo. Further, it confirmed the seed-priming activity of these strains in improving the seedling vigor and enhancing the disease protection against FCR. Also, it is suggested that S.INAT was the most effective against foot crown rot disease. Further experimentations are necessary to find out whether the induced resistance was due to either an induced state of immunity or a priming effect.

This study lays the foundation for using $T$. harzianum S.INAT as a candidate fungus for biocontrol of foot crown rot in field conditions paving the way for the exploitation of this strain in the seed coating approach at the aim to improve crop production.

\section{Abbreviations}

dpi: Days post-infection; FCR: Fusarium crown rot; ISR: Systemic resistance responses; FC: F. culmorum; CRD: Completely randomized design; VI: Vigor index; RR: The reduction rates; ANOVA: Analysis of variance; DMRT: Duncan's multiple range test; PDB: Potato-dextrose-broth; dpc: Days post-coating; ROS: Reactive oxygen species; SAR: Systemic acquired resistance

\section{Acknowledgements}

This paper and the research behind it would not have been possible without the exceptional support of the laboratory technicians.

\section{Authors' contributions}

Z.K: carried out the experiment, collected the data, performed the analysis, and wrote the paper. MBJ: helped in the writing paper. MM: helped in collecting data. SG: reviewed the manuscript. KH: helped in the identification of the Trichoderma strains. WH: reviewed the manuscript. All authors have read and approved the manuscript.

\section{Funding}

This research was financially supported by the Ministry of Research and Higher Education (grant number LRO2AGR02); and ARIMNET2 under BAC plant project

\section{Availability of data and materials \\ Not applicable}

Ethics approval and consent to participate Not applicable

\section{Consent for publication}

Not applicable

\section{Competing interests}

The authors declare that they have no competing interests.

\section{Author details}

'Laboratory of Genetics and Plant Breeding, National Institute of Agronomy of Tunis, 43, Ave. Charles Nicolle, 1082 Tunis, Tunisia. ${ }^{2}$ National Institute of Agronomy of Tunis, 43, Ave. Charles Nicolle, 1082 Tunis, Tunisia. ${ }^{3}$ National Agricultural Research Institute of Tunis, Tunis, Tunisia. ${ }^{4}$ High Agronomic Institute of Chott Mariem, Sousse, Tunisia.

Received: 15 July 2020 Accepted: 6 November 2020

Published online: 19 November 2020

\section{References}

Akbari-Vafaii A, Ketabchi S, Moradshahi A (2014) Effect of methyl jasmonate (MeJA) on biochemical responses of wheat seedlings infected by Fusarium 
culmorum. Arch. Phytopathol. Pflanzenschutz 47:1893-1904. https://doi.org/ 10.1080/03235408.2013.861638

Ben-Jabeur M, Vicente R, López-Cristoffanini C, Alesami N, Djébali N, GraciaRomero A et al (2019) A novel aspect of essential oils: coating seeds with thyme essential oil induces drought resistance in wheat. Plants 8:371. https:// doi.org/10.3390/plants8100371

Błaszczyk L, Basińska-Barczak A, Ćwiek-Kupczyńska H, Gromadzka K, Popiel D, Stępień $Ł$ (2017) Suppressive Effect of Trichoderma spp. on toxigenic Fusarium species. Pol. J. Microbiol 66:85-100. https://doi.org/10.5604/ 17331331.1234996

Bradford MM (1976) A rapid and sensitive method for the quantitation of microgram quantities of protein utilizing the principle of protein-dye binding. Anal Biochem 72:248-254. https://doi.org/10.1006/abio.1976.9999

Buriro M, Oad FC, Keerio MI, Tunio S, Gandahi AW, Hassan SWU, Oad SM (2011) Wheat seed germination under the influence of temperature regimes. Sarhad J Agric 27:539-543

Chatterjee N, Sarkar D, Sankar A, Sumita PAL, Singh H, Singh RK, Rakshit A (2018) On-farm seed priming interventions in agronomic crops. Acta Agric Slov 111 715-735. https://doi.org/10.14720/aas.2018.111.3.19

Chekali S, Gargouri S, Paulitz T, Nicol JM, Rezgui M, Nasraoui B (2011) Effects of Fusarium culmorum and water stress on durum wheat in Tunisia. Crop Prot 30:718-725. https://doi.org/10.1016/j.cropro.2011.01.007

Dendouga W, Boureghda H, Belhamra M (2016) Biocontrol of wheat Fusarium crown and root rot by Trichoderma spp. and evaluation of their cell wall degrading enzymes activities. Acta Phytopathol Entomol Hung 51:1-12. https://doi.org/10.1556/038.51.2016.1.1

Egley GH, Paul RN, Vaughn KC, Duke SO (1983) Role of peroxidase in the development of water impermeable seed coats in Sida spinosa L. Planta 157 224-232. https://doi.org/10.1007/BF00405186

El-Sobky MA, Fahmi Al, Eissa RA, El-Zanaty AM (2019) Genetic characterization of Trichoderma spp. isolated from different locations of Menoufia Egypt and assessment of their Antagonistic Ability. J Microb Biochem Technol 11:1. https://doi.org/10.4172/1948-5948.1000409

Ferrigo D, Raiola A, Piccolo E, Scopel C, Causin RJJPP (2014a) Trichoderma harzianum T22 induces in maize systemic resistance against Fusarium verticillioides. Eur J Plant Pathol 96:133-142. https://doi.org/10.4454/JPP. V9611.038

Ferrigo D, Raiola A, Rasera R, Causin R (2014b) Trichoderma harzianum seed treatment controls Fusarium verticillioides colonization and fumonisin contamination in maize under field conditions. Crop Prot 65:51-56. https:// doi.org/10.1016/j.cropro.2014.06.018

Filizola PRB, Luna MAC, de Souza AF, Coelho IL, Laranjeira D, Campos-Takaki GM (2019) Biodiversity and phylogeny of novel Trichoderma isolates from mangrove sediments and potential of biocontrol against Fusarium strains. Microb Cell Fact 18:89. https://doi.org/10.1186/s12934-019-1108-y

Gveroska B (2017) Fungicidal and stimulating effect of biopreparation Trianum-P on tobacco seedlings. Tutun/Tobacco 67

Harrach BD, Baltruschat H, Barna B, Fodor J, Kogel KH (2013) The mutualistic fungus Piriformospora indica protects barley roots from a loss of antioxidant capacity caused by the necrotrophic pathogen Fusarium culmorum. Mol Plant Microbe In 26:599-605

Jogaiah S, Abdelrahman M, Tran LSP, Ito SI (2018) Different mechanisms of Trichoderma virens-mediated resistance in tomato against Fusarium wilt involve the jasmonic and salicylic acid pathways. Mol. Plant Pathol 4:870882. https://doi.org/10.1111/mpp.12571

Jogaiah S, Abdelrahman M, Tran LSP, Shin-ichi I (2013) Characterization of rhizosphere fungi that mediate resistance in tomato against bacterial wilt disease. J. Exp. Bot. 12:3829-3842. https://doi.org/10.1093/jxb/ert212

Koycu N D, (2019) Effect on Fusarium culmorum of fungicides used in wheat seed. Proc Int Cong. Eng and Life Sci 593-601.

Lascaux É, Piron M (2009) Trianum, first stimulator of plant growth approved in France. PHM Revue Horticole 518:40-44

Li Y, Sun R, Yu J, Saravanakumar K, Chen J (2016) Antagonistic and biocontrol potential of Trichoderma asperellum ZJSX5003 against the maize stalk rot pathogen Fusarium graminearum. Indian J Microbiol 56:318-327. https://doi. org/10.1007/s12088-016-0581-9

Lorenc-Kukuła K, Wróbel-Kwiatkowska M, Starzycki M, Szopa J (2007) Engineering flax with increased flavonoid content and thus Fusarium resistance. Physiol Mol PLant P 70:38-48. https://doi.org/10.1016/j.pmpp.2007.05.005

Lutts S, Benincasa P, Wojtyla L, Kubala S, Pace R, Lechowska K, Garnczarska M (2016) Seed priming: new comprehensive approaches for an old empirical technique.
New challenges in seed biology-Basic and translational research driving seed technology. Tech Open, Rijeka, pp 1-46. https://doi.org/10.5772/64420

Mnasri N, Chennaoui C, Gargouri S, Mhamdi R, Hessini K, Elkahoui S, Djébali N (2017) Efficacy of some rhizospheric and endophytic bacteria in vitro and as seed coating for the control of Fusarium culmorum infecting durum wheat in Tunisia. Eur J Plant Pathol 147:501-515. https://doi.org/10.1007/s10658-016-1018-3

Nagaraju A, Sudisha J, Murthy SM, Ito SI (2012) Seed priming with Trichoderma harzianum isolates enhances plant growth and induces resistance against Plasmopara halstedii, an incitant of sunflower downy mildew disease. Australas Plant Pathol 6:609-620. https://doi.org/10.1007/s13313-012-0165-z

Rajeswari P (2014) Role of phenols and antioxidant enzymes in the biocontrol of Fusarium oxysporum causing Fusarium wilt on Arachis hypogaea $\mathrm{L}$. (Groundnut). Int J Agric res innov technol 4:95-104

Roberti R, Veronesi A, Cesari A, Cascone A, Di Berardino I, Bertini L, Caruso C (2008) Induction of PR proteins and resistance by the biocontrol agent Clonostachys rosea in wheat plants infected with Fusarium culmorum. Plant Sci 175:339-347. https://doi.org/10.1016/j.plantsci.2008.05.003

Saba H, Vibhash D, Manisha M, Prashant KS, Farhan H, Tauseef A (2012) Trichoderma-a promising plant growth stimulator and biocontrol agent. Mycosphere 3:524-531. https://doi.org/10.5943/mycosphere/3/4/14

Scherm B, Balmas V, Spanu F, Pani G, Delogu G, Pasquali M, Migheli Q (2013) Fusarium culmorum: causal agent of foot and root rot and head blight on wheat. Mol. Plant Pathol. 14:323-341. https://doi.org/10.1111/mpp.12011

Schöneberg T, Kibler K, Sulyok M, Musa T, Bucheli TD, Mascher F, Vogelgsang S (2018) Can plant phenolic compounds reduce Fusarium growth and mycotoxin production in cereals? Food Addit Contam A 35:2455-2470. https://doi.org/10.1080/19440049.2018.1538570

Siddiquee S (2017) Morphology-Based Characterization of Trichoderma Species. In: Practical Handbook of the Biology and Molecular Diversity of Trichoderma Species from Tropical Regions. Springer, Cham, pp 41-73

Singh RK (2010) Trichoderma: A bio-control agent for management of soil borne diseases. Retrived January 14:2016

Singleton V L, Orthofer R, Lamuela-Raventós R M (1999) Analysis of total phenols and other oxidation substrates and antioxidants by means of folin-ciocalteu reagent. In: Methods in enzymology 152-178. Academic press.

Tavares LC, Rufino CDA, Brunes AP, Friedrich FF, Barros ACSA, Villela FA (2013) Physiological performance of wheat seeds coated with micronutrients. J Seed Sci 35:28-34. https://doi.org/10.1590/S2317-15372013000100004

Tian Y, Tan Y, Yan Z, Liao Y, Chen J, De Boevre M, Wu A (2018) Antagonistic and detoxification potentials of Trichoderma isolates for control of Zearalenone (ZEN) producing Fusarium graminearum. ont Microbiol 8: 2710. doi. https:// doi.org/10.3389/fmicb.2017.02710

White TJ, Bruns T, Lee SJWT, Taylor J (1990) Amplification and direct sequencing of fungal ribosomal RNA genes for phylogenetics. PCR protocols: a guide to methods and applications, pp 315-322

\section{Publisher's Note}

Springer Nature remains neutral with regard to jurisdictional claims in published maps and institutional affiliations.

\section{Submit your manuscript to a SpringerOpen ${ }^{\circ}$ journal and benefit from:}

- Convenient online submission

- Rigorous peer review

- Open access: articles freely available online

- High visibility within the field

- Retaining the copyright to your article

Submit your next manuscript at $>$ springeropen.com 